RESEARCH ARTICLE

OPEN ACCESS

\title{
State of Depression among Nursing Professionals at Mayo Hospital, Lahore
}

\author{
Muhammad Moazzam ${ }^{1}$, Suleman Atique ${ }^{2}$, Khalid Ismail ${ }^{3}$, Asif Hanif ${ }^{4}$, Syed Amir Gilani ${ }^{5}$, Saleem \\ Muhammad Rana ${ }^{6}$, Syed Bilal Hassan ${ }^{7}$ \\ $1,2,3,4,5,6,7$ University Institute of Public Health, University of Lahore, Pakistan \\ ${ }^{2}$ Department of Health Informatics, College of Public Health and Health Informatics, University of Ha'il, Kingdom of \\ Saudi Arabia \\ ${ }^{5}$ Dean, Faculty of Allied Health Sciences, The University of Lahore, Lahore, Pakistan
}

\section{Received: 02 April,2019 \\ Accepted:09 May,2019 \\ *Correspondence to: \\ Dr. Suleman Atique,}

Email: su.atique@uoh.edu.sa

Copyright: (๑) the author(s), publisher and licensee Indian Academy of Pharmacists. This is an open-access article distributed under the terms of the Creative Commons Attribution Non-Commercial License, which permits unrestricted non-commercial use, distribution, and reproduction in any medium, provided the original work is properly cited.

Published by: OZZIE Publishers

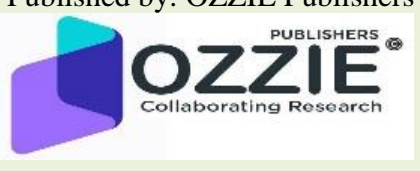

\section{Abstract}

Background: Nurses are facing different types of job-related stress like unpredicted work shifts, patients load, and critically ill patient care. Poor mental health affects the personal life of nurses but also influences their professional life. In their personal life, it may lead to drug abuse, eating disorders, cardiovascular disease, and broken relationships. Moreover, in the professional life, anxiety and depression block communications with colleagues and patients. It affects their job performance and appropriate health service to patients. Objective: To understand the state of depression among nurses at Mayo Hospital, Lahore. Methodology: It is a cross-sectional study conducted at Mayo Hospital, Lahore. Data was collected by questionnaire based on demographic profile and Beck's depression Inventory scale among 105 participants. The data was analyzed by "Statistical Package for Social Sciences" SPSS (version 20.0). Results: Our results showed that $2.8 \%$, of nursing staff experienced extreme depression, $1.9 \%$ experienced severe depression, $6.6 \%$ experienced moderate depression, $2.8 \%$ experienced borderline clinical depression, $22.8 \%$ experienced mild mood disturbance and $62.8 \%$ had normal mood. A significant relationship is found between education degree, marital status, sleeping status, physical exercise, weekly working hours and levels of depression. Conclusion: The frequency of depression is reasonably high among nurses. Prolonged exposure of mental conditions may emerge as a potential risk factor for the disease. This study provides information to health professionals for better understanding the distress of the nurses. Bearing in mind the results found it is obvious that just like physical health, it is important to focus the mental health of the health professionals including nurses.

Keywords: Depression, Anxiety, Nurses, Nursing staff, Mayo Hospital

\section{INTRODUCTION}

Depression is a mental health disorder wherein low mood and low energy can affect a person's thoughts, feelings, behavior, and sense of well-being. Depression is a mental disorder characterized by sadness, lack of confidence, adynamy, decreased energy, loss of confidence and selfesteem, sense of guilt, suicidal ideation, decreased concentration and inadequate pattern of sleep and appetite. ${ }^{1}$

Depression is a common mental disorder in many occupational sectors. It has been recognized as a major public health problem by its contribution towards the global burden of disease. Today, 350 million people from all age groups suffer from the depressive disorder. In 2000, depression has been ranked at the fourth level among the burden of disease. It is expected by the year 2020, depression will become the second most cause of disability. ${ }^{2,3}$

Mental health is one of the core components of health. World Health Organization (WHO) defines health as " $a$ state of complete physical, mental and social well-being and not merely the absence of disease or infirmity'. This emphasizes the importance of mental illnesses in the community. ${ }^{4}$ Untreated mental health illness in youth is a strong indicator of poor academic performance, awkward family life, and social engagement. It also reduces a person's natural lifespan because of associated mental conditions; for example, heart and respiratory disease and strong liking to suicide. There are different types of mental illnesses including depression, stress, anxiety, schizophrenia, and addiction disorders. ${ }^{5}$ Depression is highly associated with suicidal tendency. It is estimated that about $50 \%$ of people who have committed suicide suffered from some form of depression. According to the World Health Organization (WHO), suicidality (ideation, plans, and attempts) is the $14^{\text {th }}$ most common cause of injury and death. ${ }^{6}$

Nurses play an important role in the hospital system and the work they perform has an impact on the quality of the delivery of hospital healthcare. The nursing profession is 
universally considered a stressful occupation within the health system, and nurses are facing different types of jobrelated stress like less time for patient care, un-predicate work shifts, poor job environment, and having to face diverse challenging patients. ${ }^{7}$ It is important to note that these occupational stressors have negative effects on nursing either at a personal or professional level. At a personal level, poor mental health will lead to less commitment and broken relationships, drug abuse, thinking about suicide or committing suicide and developing body illness such as metabolic disease, eating disorder, cardiovascular disease, and musculoskeletal disease. ${ }^{8,9}$

At the professional level, poor mental health leads to block communication with colleagues and patients, affects clinical performance, liable to clinical errors, increased absences, and poor job performance. This showed that poor psychological health leads to a negativeeffect on the health of nurses but also have an impact on their job performance and quality of the services, which they provided. These unwanted desired consequences have indirect negative effects on the standard of patient care and safety. Therefore, recently hospital administrators have become more interested to improve the health issues of nurses. ${ }^{10,11}$

The prevalence rate of depression or depressive disorder among nursing professionals is higher than 20, and it is considered high when compared with the general population. In the USA, studies reported the prevalence of depression among nurses was $18 \%$ to $41 \% .^{12}$ In France, every third nurse manager in the professional field is facing depressive symptoms. ${ }^{13}$ In China, a study found the prevalence of depression was $38 \% .{ }^{14}$ In Iran, the prevalence of depression among nurses is higher than the prevalence of depression among the general population. The study revealed that the good mental health of nurses not only influences their personal life but also improves professional mistakes. Therefore, it is required to find the frequency of depression among nurses at public sector hospitals. In this study, we intend to find out the frequency of depression among nurses working at Mayo hospital, Lahore. Up-to the best of our knowledge it is the first study research on this important issue in Pakistan's healthcare set-up.

\section{METHODS}

This cross-sectional study was conducted at various departments of Mayo Hospital; Lahore over a period of six months from mid of 2018 tills its end. In the inclusion criteria, eligible participants were those who are working at mayo hospital and willing to participate in this study. In exclusion criteria, participants having less than one-year professional experience. A total of 105 questionnaires distributed among nurses. Total 105 nurses agreed to participate in this study. The response rate of this study was $100 \%$.

\section{Study Site:}

Mayo hospital Lahore is the largest and oldest hospital in Pakistan. It occupies over 54.6 acres of land and its main building has 11 gates to its boundary. Mayo hospital is known as center of excellence for public and largest hospital in South East Asia. It contains 2399 beds and serving humanity since $1871 .^{15}$

\section{Data Collection Procedure:}

Data was collected through questionnaire. The questionnaire consists of two parts. First part was demographic profile developed by researcher consisted on variable such as: age, education degree, Marital status, Sleeping Status (hours), Physical Exercise, Weekly Working hours, are you satisfied with your job? Second part of questionnaire consisted on Beck depression inventory scale. ${ }^{16}$ It is self-reported questionnaire contain 21- item with evaluation from 0-3 for each item that is used to measures levels of depression among adults. Sixty-three is the highest possible total sum for the whole test. Beck's scale categorized depression level as normal depression between score 0-10, mild depression score from 11 to 16 points, moderate depression scores from 21 to 30 points and extreme depression score from over 40 points. $^{16}$

\section{Statistical Analysis:}

We have used SPSS version 20.0 for statistical analysis of our data. We found the frequency of depression among nurses. The relationship between demographic profile and depression among nurses were measured.

\section{RESULTS}

According to Table 1, out of 105 participants the age mean and SD were 21.57 and 6.142 respectively. For education degree, 81(77.1\%) did nursing diploma, 22(21\%) participants having Bachelor degree, 1(1\%) Master degree and one $(1 \%)$ other diploma. The marital status of nurses, $63(60 \%)$ reported single and $42(40 \%)$ was married. The sleeping status (hours) of participants were, less than 8 $26(24.8 \%)$, 6-8 hours 54(51.4\%), and more than 8 was $25(23.8 \%)$. The physical activity of participants, $73(69.5 \%)$ reported yes and $32(30.5 \%)$ no. The weekly working hours of nurses, in range of 35-44 hours $18(17.1 \%)$, 45-49 hours $38(36.2 \%)$, more than 60 hours $49(46.7 \%)$. Out of 105 nurses $75.24 \%$ participant reported that they are satisfied with job, $16.19 \%$ said no satisfaction with job and $8.57 \%$ answered I do not answer. 
Table 1: Shows the participants' characteristics

\begin{tabular}{|c|c|c|}
\hline Demographic & Features & $\mathbf{N}(\%)$ \\
\hline \multicolumn{3}{|l|}{$\begin{array}{l}\text { Age } \\
\text { Mean27.88 } \\
\text { SD+6.142 }\end{array}$} \\
\hline Education Degree & Nursing diploma & $81(77.1)$ \\
\hline & $\begin{array}{l}\text { Bachelor } \\
\text { Master } \\
\text { Other }\end{array}$ & $\begin{array}{l}22(21) \\
1(1) \\
1(1)\end{array}$ \\
\hline Marital status & $\begin{array}{l}\text { Single } \\
\text { Married }\end{array}$ & $\begin{array}{l}63(60) \\
42(40)\end{array}$ \\
\hline $\begin{array}{l}\text { Sleeping } \\
\text { (hours) }\end{array}$ & $\begin{array}{l}\text { Less than } 8 \\
6-8 \\
\text { more than } 8\end{array}$ & $\begin{array}{l}26(24.8) \\
54(51.4) \\
24(23.8)\end{array}$ \\
\hline Physical Exercise & $\begin{array}{l}\text { Yes } \\
\text { No }\end{array}$ & $\begin{array}{l}73(69.5) \\
32(32.5)\end{array}$ \\
\hline $\begin{array}{l}\text { Weekly Working } \\
\text { hours }\end{array}$ & $\begin{array}{l}35-44 \\
45-49 \\
\text { more than } 60\end{array}$ & $\begin{array}{l}18(17.1) \\
38(36.2) \\
49(46.7)\end{array}$ \\
\hline $\begin{array}{l}\text { Are you satisfied with } \\
\text { your job? }\end{array}$ & $\begin{array}{l}\text { Yes } \\
\text { No } \\
\text { I do not answer }\end{array}$ & $\begin{array}{l}79(75.25) \\
9(8.75) \\
17(16.19)\end{array}$ \\
\hline
\end{tabular}

According to Table 2, distribution of the nurses by levels of depression showed that nurses experience extreme depression $2.8 \%$, severe depression $1.9 \%$, moderate depression $6.6 \%$, borderline clinical depression $2.8 \%$, mild mood disturbance $22.8 \%$ and normal mood was $62.8 \%$.
Participants total Beck's Depression inventory scores ranged from 0 to 43 with a mean score of $9.74+9.686$.

Table 2: Distribution of the students by Levels of Depression $(n=105)$

\begin{tabular}{|l|l|l|}
\hline Variable & Frequency $(\mathbf{N})$ & Percent $(\%)$ \\
\hline Normal Mood (score 0 - 10) & 66 & 62.8 \\
\hline Mild Mood Disturbance (score 11 - 16) & 24 & 22.8 \\
\hline Borderline Clinical Depression (score 17 - 20) & 3 & 2.8 \\
\hline Moderate Depression (score 21 - 30) & 7 & 6.6 \\
\hline Severe Depression (score 31 - 40) & 2 & 1.9 \\
\hline Extreme Depression (score 40 and above) & 3 & 2.8 \\
\hline
\end{tabular}

\section{DISCUSSION}

In this study, we examined the frequency of depression among nurses working at Mayo Hospital, Lahore. Nurses are known as the backbone of our healthcare system. They take care of the patient and work under constant mental and physical stress. In order to perform their duty, they were required to be provided stress-free environment to keep them satisfied with their job. Otherwise, it creates depression among them and affects the patient care delivery. ${ }^{17,18}$ The current study results indicated that $2.8 \%$ participant experienced extreme depression, $1.9 \%$ of participants experienced severe depression, $6.6 \%$ of participants experienced moderate depression and $22.8 \%$ experienced mild mood depression.

In relation to the present study, the research done by Gao and Pan (2012) revealed that nurses experienced $74.3 \%$ mild depression. ${ }^{19}$ In addition, in another study researcher Risal \& Sanjel (2016) reported that among their participants, $27.4 \%$ was mildly depressed, $9 \%$ was moderately depressed, and $1.4 \%$ was severely depressed. ${ }^{20}$ Although we obtained high frequency of mild and moderate depression scores among our participants but incidence of severe depression was seen less. Absence of lower prevalence of severe depression was also observed in other studies. ${ }^{16,21}$ Low incidence of severe depression in the present study can be explained by the fact that the participants having mild to moderate depressive symptoms seek the help of the psychiatrists available in their hospitals; hence, very few tend to be severely depressed.

Analysis of the mean scores of individual item of the Beck Inventory scale revealed that mood symptoms like sadness and agitation, and fatigability loaded maximally for depression; fitting appropriately with the major criteria of depression. ${ }^{17}$ It shows that our participants think less about suicide even when they are depressed; but, this tough may come up with the advancement in their age.

Based on this study, there are many demographic factors which play pivotal role in creating depression among nurses. The findings exhibited that $81(77.1 \%)$ nursing having nursing diploma. Studies done by Cheung \& Lee (2018) reported that low level of education degree experience more depression and anxiety. ${ }^{22}$ 
Quality of sleep is the main factor for developing depression and anxiety among nurses. The finding of present study showed that $26(24.8 \%)$ nurse sleep less than 8 hours. It is observed that bad quality of sleep disturbed the person mood and daily routine life. Studies carried out by Dinis \& Bragança (2018) and Dietrich \& Francis-Jimenez (2016) regarding the quality of sleep also reported that sleep quality had a powerful impact on developing depression and anxiety. $^{23,24}$

Physical exercise is used to decrease depression and anxiety. Results of present study showed that $73(69.5 \%)$ participants were doing physical exercise. This finding is supported by the research done by Freitas and Carneseca (2014) who reported that nurses who were doing physical exercise, experienced less depression and anxiety. Physical exercise influenced the person mood and mind. ${ }^{25}$

In the present study, the majority of nurse 49 (46.1\%) reported working more than 60 hours per week. A study carried out by Botha and Gwin (2015) showed that 'more weekly working hours' lead to anxiety and depression among nurses. ${ }^{26}$ Job environment stress and lifestyle that led to poor job performance and negatively effect on the health of nurses. From this study, it was clear that depression among nurses were currently prevalent and widespread issue across the country. Nursing, working at a hospital are facing transient period of their life in which they are moving from adolescence to adulthood and can be one of the most stressful periods in an individual's life. So, special attention and clinical services should be provided who have reported the symptoms of depression.

\section{CONCLUSION}

The frequency of anxiety and depression are reasonably high among nurses. Prolong exposure such mental conditions may emerge as a potential risk factor for the disease. This study provides preliminary information to health professionals for better understanding the distress of the nurses. Bearing in mind the results found it is obvious that just like physical health, it is important to focus on the mental health of the nurses. By evaluating the contribution of these risk factors upon the development of professional depression, in a stressful job i.e. nurses. It is important to provide them supportive job environment. Nurses should be encouraged to support the evidence of good nutrition and exercise.

Based on the Findings of this Study, the Following Recommendations are suggested

- There should be regularly scheduled mental and physical health check-ups of nurses.

- $\quad$ To raise awareness regarding the importance of mental health in nurses, one special day should be celebrated to encourage them to express their mental problem.

- Launch programs for prevention of anxiety and depression-like physical health and nutrition program among nurses.

- The health departments and hospital management should make strategies for the improvement of mental health of nurses.

\section{LIMITATION}

This study did not include nurses whose experience is less than one year. This is a convenience study and can reduce the generalization of results. Many nurses refused to participate in this study. Therefore, it may not be representative of the general nursing community. There may be information errors, as nurses can report on good habits such as exercise and there may be underlying on certain unacceptable habits, such as multiple hours a week.

\section{ETHICAL APPROVAL}

Permission was sought from Medical Superintendent of Mayo Hospital, Lahore for data collection. Approval of the Institutional Review Board Committee (IRB) at The University of Lahore (Ref No: IRB-UOL-FAHS/414/2019) was also granted. All the participation was voluntary and they had the right to withdraw from the study at any time. After explanation of the purpose of the study, data was collected. There was neither any known harm resulted from participation in the study nor any gained entitlement. The questionnaire was completely anonymous and there was no identifying data collected. All collected data were confidential and used only for the purpose of the current research.

\section{CONFLICT OF INTERESTS}

The authors declare that they have no conflict of interests with any organization regarding the materials discussed in this manuscript.

\section{ACKNOWLEDGMENT}

Appreciations to all nurses' participants who voluntarily participated in the study and shared their experience.

\section{AUTHORS CONTRIBUTION}

Muhammad Moazzam conceived, designed and did statistical analysis, data collection manuscript writing \& editing of the manuscript.

Dr. Khalid Ismail, Dr. Suleman Atique, Dr. Syed Amir Gilani and Dr. Saleem M Rana conceived, designed, editing of manuscript, review and final approval of the manuscript.

Dr. Asif Hanif approved the statistical analysis.

Grant Support \& Financial Disclosures

None

\section{REFERENCES}

[1] Godil A, Mallick MSA, Adam AM, Haq A, Khetpal A, Afzal R, et al. Prevalence and Severity of Depression in a Pakistani Population with at least One Major Chronic Disease. Journal of Clinical and Diagnostic Research : JCDR. 2017;11(8):Oc05-10.

[2] Andreeva E, Magnusson Hanson LL, Westerlund H, Theorell T, Brenner MH. Depressive symptoms as a cause and effect of job loss in men and women: evidence in the context of organisational downsizing from the Swedish Longitudinal Occupational Survey of Health. BMC public health. 2015;15:1045.

[3] Woledesenbet MA, Shumet Mekonen S, Sori LM, Abegaz TM. Epidemiology of Depression and Associated Factors among Asthma Patients in Addis Ababa, Ethiopia. Psychiatry journal. 2018;2018:5934872-. 
[4] WHO. Frequently asked questions. 2013:Availiable at: http://www.who.int/suggestions/faq/en/. Retrieved on Oct 2018.

[5] Chon MW, Lee J. Prescription Pattern of Antidepressants for Children and Adolescents in Korea Based on Nationwide Data. 2017;32(10):1694701.

[6] Li H, Luo X, Ke X, Dai Q, Zheng W, Zhang C, et al. Major depressive disorder and suicide risk among adult outpatients at several general hospitals in a Chinese Han population. 2017;12(10):e0186143.

[7] Jaradat Y, Nijem K, Lien L, Stigum H, Bjertness E, Bast-Pettersen R. Psychosomatic symptoms and stressful working conditions among Palestinian nurses: a cross-sectional study. Contemporary nurse. 2016;52(4):381-97.

[8] Mata DA, Ramos MA, Bansal N, Khan R, Guille C, Di Angelantonio E, et al. Prevalence of Depression and Depressive Symptoms Among Resident Physicians: A Systematic Review and Meta-analysis. Jama. 2015;314(22):2373-83.

[9] Rotenstein LS, Ramos MA, Torre M, Segal JB, Peluso MJ, Guille C, et al. Prevalence of Depression, Depressive Symptoms, and Suicidal Ideation Among Medical Students: A Systematic Review and MetaAnalysis. Jama. 2016;316(21):2214-36.

[10] Saeedi Shahri SS, Ghashghaee A, Behzadifar M, Bragazzi NL, Behzadifar M, Mousavinejad N, et al. Depression among Iranian nurses: A systematic review and meta-analysis. Medical journal of the Islamic Republic of Iran. 2017;31:130.

[11] Wang LJ, Chen CK, Hsu SC, Lee SY, Wang CS, Yeh WY. Active job, healthy job? Occupational stress and depression among hospital physicians in Taiwan. Industrial health. 2011;49(2):173-84.

[12] Saeedi Shahri SS. Depression among Iranian nurses: A systematic review and meta-analysis. 2017;31:130.

[13] Nourry N, Luc A, Lefebvre F, Sultan-Taieb H, Bejean S. Psychosocial and organizational work environment of nurse managers and self-reported depressive symptoms: cross-sectional analysis from a cohort of nurse managers. International journal of occupational medicine and environmental health. 2014;27(2):252-69.

[14] Gong Y, Han T, Yin X, Yang G, Zhuang R, Chen Y, et al. Prevalence of depressive symptoms and workrelated risk factors among nurses in public hospitals in southern China: a cross-sectional study. Scientific Reports. 2014;4:7109.

[15] Brief History and Introduction about Mayo Hospital. 2011: Available at: https://www.mayohospital.gop.pk/about.php Retrieved on Oct 2018.

[16] Lee EH, Lee SJ, Hwang ST, Hong SH, Kim JH. Reliability and Validity of the Beck Depression
Inventory-II among Korean Adolescents. Psychiatry Investigation. 2017;14(1):30-6.

[17] Gao YQ, Pan BC, Sun W, Wu H, Wang JN, Wang L. Anxiety symptoms among Chinese nurses and the associated factors: a cross sectional study. BMC psychiatry. 2012;12:141

[18] Tran TTT, Nguyen NB, Luong MA, Bui THA, Phan TD, Tran VO, et al. Stress, anxiety and depression in clinical nurses in Vietnam: a cross-sectional survey and cluster analysis. International journal of mental health systems. 2019;13:3.

[19] Gao YQ, Pan BC, Sun W, Wu H, Wang JN, Wang L. Depressive symptoms among Chinese nurses: prevalence and the associated factors. Journal of advanced nursing. 2012;68(5):1166-75.

[20] Risal A, Sanjel S, Sharma PP. Study of Depression among the Nursing Students in a University Medical College of Nepal. Kathmandu University medical journal (KUMJ). 2016;14(55):264-8.

[21] Cheung T, Yip PS. Depression, Anxiety and Symptoms of Stress among Hong Kong Nurses: A Cross-sectional Study. International journal of environmental research and public health. 2015;12(9):11072-100.

[22] Cheung T, Lee PH, Yip PSF. The association between workplace violence and physicians' and nurses' job satisfaction in Macau. PloS one. 2018;13(12):e0207577.

[23] Dinis J, Bragança M. Quality of Sleep and Depression in College Students: A Systematic Review. Sleep science (Sao Paulo, Brazil). 2018;11(4):290-301.

[24] Dietrich SK, Francis-Jimenez CM, Knibbs MD, Umali IL, Truglio-Londrigan M. Effectiveness of sleep education programs to improve sleep hygiene and/or sleep quality in college students: a systematic review. JBI database of systematic reviews and implementation reports. 2016;14(9):108-34.

[25] Freitas AR, Carneseca EC, Paiva CE, Paiva BS. Impact of a physical activity program on the anxiety, depression, occupational stress and burnout syndrome of nursing professionals. Revista latinoamericana de enfermagem. 2014;22(2):332-6.

[26] Botha E, Gwin T, Purpora C. The effectiveness of mindfulness based programs in reducing stress experienced by nurses in adult hospital settings: a systematic review of quantitative evidence protocol. JBI database of systematic reviews and implementation reports. 2015;13(10):21-9.

Cite article as: Muhammad Moazzam, Suleman Atique, Khalid Ismail, Asif Hanif, Syed Amir Gilani, Saleem Muhammad Rana, Syed Bilal Hassan. State of Depression among Nursing Professionals at Mayo Hospital, Lahore. Res Pharm Healt Sci.2019;5(2):142-147., doi: https://doi.org/10.32463/rphs.2019.v05i02.04 